\title{
CERVICAL SPONDYLOTIC MYELOPATHY: CLINICAL CASES AND PHYSIOTHERAPY
}

\author{
MIELOPATIA ESPONDILÓTICA CERVICAL: CASOS CLÍNICOS E A FISIOTERAPIA \\ MIELOPATÍA ESPONDILÓTICA CERVICAL: CASOS CLÍNICOS Y FISIOTERAPIA
}

Rafael de Almeida Oliveira, ${ }^{1}$ Karime Fares, ${ }^{2}$ Daniela Schiavon, ${ }^{2}$ Pauliana Carolina Souza, ${ }^{2}$ Gustavo José Luvizutto, ${ }^{1}$

luciane Aparecida Pascucci Sande de Souza'

1. Universidade Federal doTriângulo Mineiro (UFTM), Uberaba, MG, Brazil.

2. Universidade de Ribeirão Preto (UNAERP), Ribeirão Preto, SP, Brazil.

\begin{abstract}
The aims of this article are to present cervical spondylotic myelopathy, a spinal condition caused by bony, ligament and disc alterations that results in spinal cord compression leading to progressive degeneration of the spinal cord, and to describe the possible physiotherapeutic interventions. The pathology has different forms of progression and affected areas, which contributes to the diversity of clinical presentations. This work presents two evaluations of three patients diagnosed with this disease, at different times, to compare the severity, the affected regions, and the evolution of each one. Subsequently, it describes the most appropriate physiotherapeutic treatment for this illness, demonstrating its wide variability according to the signs and symptoms presented. Level of Evidence: IV. Case series.
\end{abstract}

Keywords: Spinal cord compression; Physical therapy specialty; Spinal cord.

\section{RESUMO}

O objetivo deste artigo é apresentar a Mielopatia Espondilótica Cervical, uma afecção da coluna vertebral causada por alterações ósseas, ligamentares e discais, que resultam na compressão medular, desencadeando a degeneração progressiva da medula, e descrever possíveis intervenções fisioterapêuticas. A patologia tem diferentes formas de progressão e áreas de comprometimento, o que contribui com a diversidade de quadros clínicos. Serão apresentadas duas avaliações de 3 pacientes com diagnóstico desta doença, em momentos diferentes, com o intuito de comparar a gravidade, as regiões comprometidas e a evolução de cada um. Posteriormente, é descrito o tratamento fisioterapêutico mais apropriado para esta doença, demonstrando também sua grande variabilidade de acordo com os sinais e sintomas apresentados. Nível de evidência: IV Tipo de estudo: Série de casos.

Descritores: Compressão da medula espinhal; Fisioterapia; Medula Espinhal.

\section{RESUMEN}

Los objetivo de este artículo son presentar la mielopatía espondilótica cervical, una afección de la columna vertebral causada por alteraciones óseas, ligamentos y discales, que resultan en la compresión medular, desencadenando la degeneración progresiva de la médula y describir posibles intervenciones fisioterapéuticas. La patología tiene diferentes formas de progresión y áreas de compromiso, lo que contribuye a la diversidad de cuadros clínicos. Se presentarán dos evaluaciones de tres pacientes con diagnóstico de esta enfermedad en momentos diferentes con el objetivo de comparar la gravedad, las regiones comprometidas y la evolución de cada uno. Posteriormente se describe el tratamiento fisioterapéutico más apropiado para esta enfermedad, demostrando también su gran variabilidad de acuerdo con los signos y síntomas presentados. Nivel de evidencia IV. Serie de casos.

Descriptores: Compresión de la médula espinal; Fisioterapia; Medula espinal.

\section{INTRODUCTION}

Cervical spondylotic myelopathy (CSM) is defined as a series of signs and symptoms that result in anatomical and physiological changes in the vertebral column, leading to spinal cord compression. The clinical symptoms are characterized by progressive deterioration of the spinal cord functions. Besides the signs and symptoms, for confirmation of the diagnosis, the patient must present spinal cord compression, proven by computed tomography, MRI or myelography, as well as radiographic evidence of spondylotic damage to the spinal cord. ${ }^{1,2}$ In most cases, the natural progression occurs in bursts of exacerbation of symptoms followed by periods of stability. The clinical symptoms rarely improve; however, there have been reports of cases in which this period of stability was not present, and the patient's condition declined continuously and slowly. On the other hand, in a small number of cases, the progression may be acute and rapid. ${ }^{3,4}$

The cause of CSM is not well-defined, but it is known that changes in the bones, ligaments and discs act as a trigger for progressive spinal cord degeneration, which leads to direct compression (dynamic or static), often associated with circulatory damage. Nearly all individuals, at around thirty years of age, present microscopic degeneration of the intervertebral discs. ${ }^{5}$ In fact, it is believed that the whole process of spondylotic changes begins with disc dehydration, which is

Study conducted at Universidade de Ribeirão Preto (UNAERP), Ribeirão Preto, SP, Brazil.

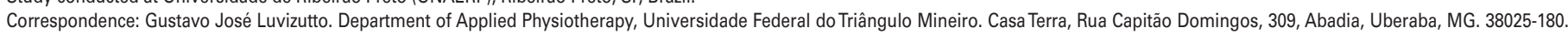
gustavo.luvizutto@uftm.edu.br 
related to loss of proteoglycans, elasticity and disc material ${ }^{6-8}$ as well as other biochemical changes involving the keratin and chondroitin sulfate. ${ }^{2}$ These biomechanical changes in the discs result in reduced disc space, and this, together with the fact that the disc dehydration tends to herniate, leads to changes such as bone neoformation in the vertebral bodies, usually subsequently, causing anterior spinal cord compression. ${ }^{7}$ Hypertrophy and calcification of the Yellow ligament occur, ${ }^{8}$ contributing to posterolateral spinal cord compression, ${ }^{7}$ but this mainly occurs with the posterior longitudinal ligament, ${ }^{9}$ exacerbating this compression. ${ }^{7}$ This ossified ligament becomes a thickened mass, which may be present at one level only, either in intermittent or continuous form, and in more severe cases, ossification of the dura mater also occurs, which can lead to the formation of fistulas of cerebrospinal fluid. Alongside this process, there is also facet joint hypertrophy and arthrosis of the intervertebral and zygapophysial joints, resulting in stenosis of the vertebral canal. ${ }^{2}$

As a result of more severe spondylotic changes, patients often develop hyperkyphosis, further aggravating the spinal cord compression ${ }^{2}$ and also loss of lordotic curvature, causing an increase in pressure in the anteroposterior direction. ${ }^{7}$ Spondylosis also causes hypermobility of the segments located above the rigid levels of the spinal cord, and is another cause of spinal cause compression. ${ }^{2}$ There is also the genetic factor, which leads to congenital narrowing of the spinal cord, increasing the chances of developing the disease. ${ }^{10,11}$ The pathology may also occur due to dynamic compression; when the neck is extended, the ligamentum flavum pinches the spinal cord against the osteophytes, ${ }^{12}$ while flexion reduces the anteroposterior diameter, aggravating the compression against them; ${ }^{13}$ lateral movements compress the nerve roots leading to radicular symptoms. ${ }^{7}$ Finally, in addition to the above, there is also decreased blood flow, causing ischemia of the spinal cord; ${ }^{12}$ this decrease may also be in some important blood source, such as venous drainage, which leads to neuroischemic myelopathy, usually occurring in the anterior spinal cord. ${ }^{7}$ When these changes are present, the patient becomes symptomatic only when $30 \%$ of the spinal cord is affected. ${ }^{7}$

The treatment of the disease is basically through decompression surgery, particularly in severe and moderate cases. ${ }^{2}$ However, the recovery of spinal cord functions after surgery depends on the degree of spinal cord degeneration at the time of surgery. ${ }^{14,15}$ There is also conservative treatment, which is given according to the functions lost, with the aim of treating them and avoiding worsening of the compression already present. Due to the evolution, it is important to reevaluate the spinal cord degeneration every 6 to 12 months. ${ }^{2}$ The aim of this study was to describe the evolution of CSM through the report of clinical symptoms of patients who developed this disease, as well as presenting and discussing the possible physiotherapeutic conducts to be adopted.

\section{METHODS}

This is a case series study, approved by the Institutional Review Board of Universidade de Ribeirão Preto - UNAERP (n.044/2005), with an Informed Consent Form signed by all the participants. The medical records were analyzed of all patients with CSM who attended the Physiotherapy Clinic at the CECEB (Electro Bonini Clinical Center) of Universidade de Ribeirão Preto-UNAERP in the last ten years. Only three patients were found; only the first and final evaluations were analyzed, as well as the daily records of clinical evolution. Only the items of the evaluations that presented changes were evaluated. The disease evolution was classified using the following scales:

Nurick Scale for Cervical Myelopathy (Table 1) - Assesses the patient's ability to walk without support, scoring from 0 to 5 , where the higher the score, the better the patient's ability to walk. ${ }^{16}$

Cervical Spondylotic Myelopathy scale of the Japanese Orthopaedic Association (JOA) (Table 2) - Validated in 1976 by the JOA, scores the motor function of each upper limb (Item I) and lower limb (Item II), the sensitivity of each upper limb (Item III A), lower limb (Item III B), and trunk (Item III C) and bladder function (Item IV), according to specific functions that the patient is able to perform. The maximum score indicating normality is $17 .{ }^{17,18}$

\section{RESULTS}

\section{Case 1}

Patient presented with onset of the pathological symptoms with degenerative processes of the spine, and progressively decreasing sensitivity and movements. Evolved to surgical treatment with placement of graft and prosthesis in the left anterolateral region of C4. Initially the lesion affected sensitivity, muscle strength, and range of movement (ROM) of the upper limbs, which subsequently progressed to include the lower limbs.

Initial evaluation: Patient arrived in a wheelchair, obtaining a grade of 5 on the Nutrick scale (Table 1). Presented with elastic hypertonia of the upper and lower limbs. A decrease in sensitivity in the cervical region, upper limbs, ventral and dorsal region of the trunk, and anterolateral part of both lower limbs proximally, (Figure 1) presence of hyperreflexia in the brachial triceps muscle. The active ROM was decreased in the pinch test with the left hand, flexion of the shoulder and elbow, pronation, supination and dorsiflexion. In the evaluation of Activities of Daily Living (ADL) the patient was capable of eating independently, but was not able to turn over while lying. During the evaluation of muscle strength, it was observed that the main muscles of the upper limbs had a score of $3+$, which means that the patient is able to overcome the action of gravity associated with a slight resistance. The majority of the main muscles of the lower limbs had muscle strength of grade 3, overcoming only the action of gravity. According to the evaluation of functions, the patient obtained 7 points out of a total of 17 on the Evaluation Scale of the JOA, (Table 2) The goals outlined for the treatment were: to decrease the spasticity, facilitate turning over while lying, stimulate sensitivity, improve functionality and independence in day-to-day tasks, promote relaxation of the cervical musculature, strength the gluteus and abdominals, and lengthen the muscle that was shortened due to the seated position.

Final evaluation: After 1 year and 2 months from the onset of symptoms, the patient reported that he/she no longer eats alone or turns over while lying, being dependent for all the ADLs. The hypertonia was the same in the upper and lower limbs, but at this moment, it is also present in the trunk. In relation to sensitivity, an improvement was observed. (Figure 1) The patient presented areflexia in the Achilles, bicipital, tricipital and patellar reflexes bilaterally. The muscle strength test showed evident deterioration of the overall muscle strength of the upper limbs, with the exception of the elbow flexors and extensors, and a slight improvement and maintenance of strength in the lower limbs. Muscle retraction was present in all the limbs. The patient could still move around using a wheelchair, thus obtaining the same score in the Nurick scale. (Table 1) According to the JOA Evaluation scale, the patient presented significant worsening in the score, which increased from a final score of 7 to 5 . (Table 2) The goals outlined in this phase were: Preventing deformities, improving flexibility and muscle strength in general, maintaining independence, and improving trunk balance while sitting.

Table 1. Nurick score in the 3 patients.

\begin{tabular}{|c|c|c|c|c|}
\hline Clinical Signs & Grade & $\begin{array}{c}\text { Patient } \\
1 \\
\end{array}$ & $\begin{array}{c}\text { Patient } \\
2 \\
\end{array}$ & $\begin{array}{c}\text { Patient } \\
3 \\
\end{array}$ \\
\hline $\begin{array}{c}\text { Radicular signs, without } \\
\text { evidence of spinal cord } \\
\text { impairment }\end{array}$ & Grade 0 & \multirow{3}{*}{$\begin{array}{c}1^{\text {st }} \\
\text { evaluation } \\
\text { Grade } 5\end{array}$} & \multirow{3}{*}{$\begin{array}{c}1^{\text {st }} \\
\text { evaluation } \\
\text { Grade } 5\end{array}$} & \multirow{3}{*}{$\begin{array}{c}1^{\text {st }} \\
\text { evaluation } \\
\text { Grade } 4\end{array}$} \\
\hline $\begin{array}{c}\text { Signs of spinal cord } \\
\text { impairment with normal gait }\end{array}$ & Grade 1 & & & \\
\hline Impaired gait, able to work & Grade 2 & & & \\
\hline $\begin{array}{l}\text { Impaired gait, unable to work, } \\
\text { but walks without support }\end{array}$ & Grade & \multirow{3}{*}{$\begin{array}{l}2^{\text {nd }} \\
\text { evaluation } \\
\text { Grade } 5\end{array}$} & \multirow{3}{*}{$\begin{array}{c}2^{\text {nd }} \\
\text { evaluation } \\
\text { Grade } 5\end{array}$} & \multirow{3}{*}{$\begin{array}{c}2^{\text {nd }} \\
\text { evaluation } \\
\text { Grade } 4\end{array}$} \\
\hline Able to walk unaided & Grade 4 & & & \\
\hline Wheelchair or bedridden & Grade 5 & & & \\
\hline
\end{tabular}




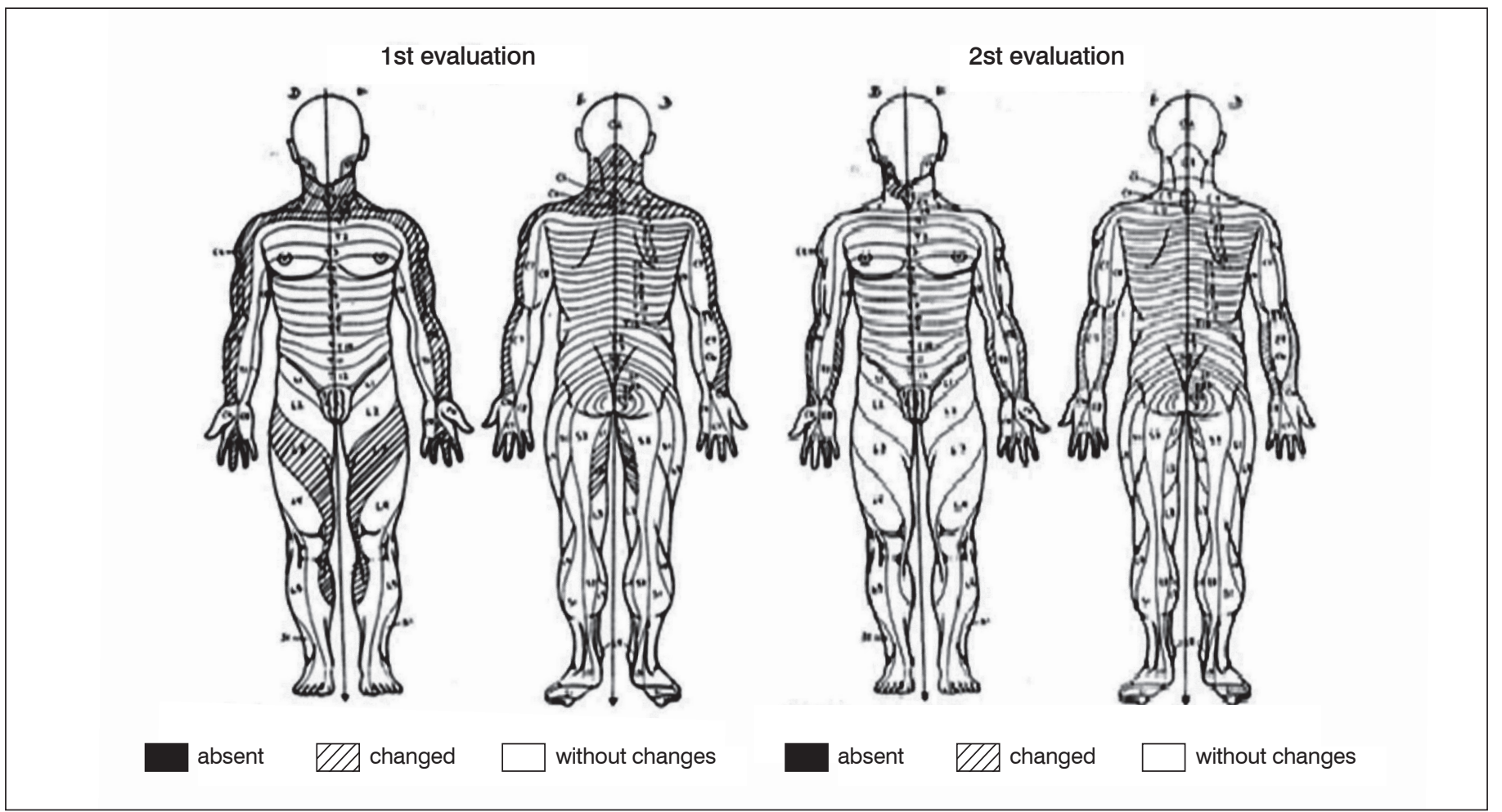

Figure 1. Sensory maps of patient 1 in the initial and final evaluations.

\section{Case 2}

Patient reported numbness in the right side of the body, associated with loss of sensitivity of the lower limbs. CSM was diagnosed, compatible with an incomplete lesion at level C7. The patient evolved to requiring surgery, but without changes in the condition, continuing with a physiotherapeutic diagnosis of quadriplegia. The patient complained of limited movement in the lower and upper limbs, not being able to walk, and being dependent for most ADLs. Initial evaluation: Patient presented with a physiotherapeutic diagnosis of spastic quadriplegia, with diffuse changes in sensitivity in the lower and upper limbs. (Figure 2) In the evaluation of the ADLs the patient was dependent for most of them, and could move around using a wheelchair, thus scoring 5 on the Nurick scale (Table 1), but was not able to turn over while lying. As for the deep reflexes, the right patellar was decreased and the left normal; the right bicipital and tricipital were reduced, and the left were normal. The right Achilles reflex was missing and the left was decreased. And as for the skin reflexes, the abdominal cutaneous was absent, and Babinski was positive bilaterally. The patient presented a full range of movement in right shoulder abduction, left elbow flexion, left hip flexion, flexion, and extension of the left and right knees, and left plantar flexion; the remainders were incomplete. In the assessment of muscle strength, the patient presented grade 3 for overall strength; only the adductor and abductor muscles of the hip showed grade 2 bilaterally, and the wrist extensors of the right upper limb presented grade 0. Moderate shortening was observed of the upper and lower limbs. In the evaluation of functions using the JOA scale, the patient obtained a final score of 6 points. (Table 2) The treatment goals were: to gain range of movement and strength in the upper and lower limbs, to promote an improvement in trunk balance and coordination, and to improve functionally, overall and in the wheel chair.

Final evaluation: After 4 years, the patient presented minimal functional movements, reported that he/she could eat independently, but did not touch the wheelchair, remaining with the same Nurick score (Table 1). Patient presented with a flexor pattern of the upper limbs and started to "roll on a block" with help. Presented worsening of sensitivity in the lower limbs. (Figure 2) With regard to the deep reflexes, the patellar and bicipital showed increases bilaterally.
The patient presented incomplete passive and active ranges of movement of the shoulder, elbow, wrist, and limbs, bilaterally. With respect to muscle strength, there was a visible reduction in overall muscle strength, with preserved strength only in the elbow flexor muscles, hip adductor and hip abductor, all bilaterally. There was an improvement in strength in the right wrist extensors, from grade 0 to grade 1. The shortening of the upper and lower limbs went from moderate to severe. Due to the worsening of sensitivity in item III $B$ of the JOA Evaluation scale, the patient presented a decreased final score, from 6 to 5 . (Table 2) The goals outlined in this phase were: postural orientation, diaphragmatic respiratory rehabilitation, and maintenance of quality of life.

\section{Case 3}

The symptoms started with the patient presenting difficulty walking, and reports of weakness of the left lower limb. He/she was diagnosed with CSM, and 7 months after the diagnosis, underwent surgical correction by means of a laminectomy, without any complications, but with continued loss of function of the left lower and upper right limbs. The patient had a previous history of stroke and acute myocardial infarction, followed by minimal sequelae.

Initial evaluation: Patient walking with support, but only for short distances, presenting hemiparetic gait with short steps, thus classified as Nurick grade 4. (Table 1) In the ADL, he/she had difficulty sitting down and standing up, and it was observed that the patient could not turn over while lying. The temperature in the left lower limb was lower than that of the other members. Normal tropism was seen in the limbs, trunk and face, with hypotonia in the right upper limb and left lower limb. The Babinski reflex was positive on the right and absent on the left. Patellar and Achilles areflexia on the left and bicipital and tricipital areflexia on the right. Tests for changes in sensitivity found changes in the right lower limb, with preservation of the other areas. (Figure 3) Patient presented incomplete range of movement only in the right wrist, hand and fingers, and also in the left knee, ankle, foot and toes. Patient had severe limitation in all movements of the cervical spine, and moderate limitation in the lumbar region. In the evaluation of muscle strength, grade 3 was found in most of the major muscles of the upper limbs, bilaterally, 
Table 2. Cervical Spondylotic Myelopathy scale of the JOA applied in the 3 patients.

\begin{tabular}{|c|c|c|c|c|c|c|c|}
\hline \multirow{2}{*}{$\begin{array}{c}\text { I Upper extremity function } \\
0\end{array}$} & \multirow[b]{2}{*}{$\begin{array}{l}\text { Impossible to eat with either } \\
\text { chopsticks or spoon }\end{array}$} & \multicolumn{2}{|c|}{ Patient 1} & \multicolumn{2}{|c|}{ Patient 2} & \multicolumn{2}{|c|}{ Patient 3} \\
\hline & & $\begin{array}{l}\text { Evaluation } \\
1\end{array}$ & $\begin{array}{l}\text { Evaluation } \\
\quad 2\end{array}$ & $\begin{array}{l}\text { Evaluation } \\
\qquad 1\end{array}$ & $\begin{array}{l}\text { Evaluation } \\
\quad 2\end{array}$ & $\begin{array}{l}\text { Evaluation } \\
1\end{array}$ & $\begin{array}{c}\text { Evaluation } \\
1\end{array}$ \\
\hline 1 & $\begin{array}{l}\text { Possible to eat with spoon, but not } \\
\text { with chopsticks }\end{array}$ & \multirow{4}{*}{2} & \multirow{4}{*}{0} & \multirow{4}{*}{1} & \multirow{4}{*}{1} & \multirow{4}{*}{1} & \multirow{4}{*}{1} \\
\hline 2 & $\begin{array}{c}\text { Possible to eat with chopsticks, but } \\
\text { inadequately }\end{array}$ & & & & & & \\
\hline 3 & $\begin{array}{l}\text { Possible to eat with chopsticks, but } \\
\text { awkwardly }\end{array}$ & & & & & & \\
\hline 4 & Normal & & & & & & \\
\hline \multicolumn{8}{|l|}{ II Lower extremity function } \\
\hline 0 & Impossible to walk & \multirow{5}{*}{0} & \multirow{5}{*}{0} & \multirow{5}{*}{0} & \multirow{5}{*}{0} & \multirow{5}{*}{1} & \multirow{5}{*}{1} \\
\hline 1 & Needs cane or aid on flat ground & & & & & & \\
\hline 2 & Needs cane or aid only stairs & & & & & & \\
\hline 3 & $\begin{array}{c}\text { Possible to walk without cane or aid, } \\
\text { but slowly }\end{array}$ & & & & & & \\
\hline 4 & Normal & & & & & & \\
\hline \multicolumn{8}{|l|}{ III Sensory function } \\
\hline \multicolumn{2}{|l|}{ A. Upper extremity } & \multirow{4}{*}{1} & \multirow{4}{*}{1} & \multirow{4}{*}{1} & \multirow{4}{*}{1} & \multirow{4}{*}{1} & \multirow{4}{*}{2} \\
\hline 0 & Apparent sensory loss & & & & & & \\
\hline 1 & Minimal sensory loss & & & & & & \\
\hline 2 & Normal & & & & & & \\
\hline \multicolumn{8}{|l|}{ B. Lower extremity } \\
\hline 0 & Apparent sensory loss & \multirow{3}{*}{2} & & & & & \\
\hline 1 & Minimal sensory loss & & 2 & 1 & 0 & 1 & 1 \\
\hline 2 & Normal & & & & & & \\
\hline C. Trunk & & & & & & & \\
\hline 0 & Apparent sensory loss & & & & & & \\
\hline 1 & Minimal sensory loss & 1 & 1 & 2 & 2 & 2 & 2 \\
\hline 2 & Normal & & & & & & \\
\hline IV Bladder function & & & & & & & \\
\hline 0 & Complete retention & & & & & & \\
\hline 1 & Severe disturbance & & & & & & \\
\hline-1 & Inadequate evacuation of the bladder & & & & & & \\
\hline-2 & Straining & & & & & & \\
\hline-3 & Dribbling of urine & 1 & 1 & 1 & 1 & 3 & 3 \\
\hline 2 & Mild disturbance & & & & & & \\
\hline-1 & Urinary frequency & & & & & & \\
\hline-2 & Urinary hesitancy & & & & & & \\
\hline 3 & Normal & & & & & & \\
\hline
\end{tabular}

with the exception of the elbow flexor and shoulder extensor muscles, both on the right side. In the lower limbs, muscle strength is diffusely decreased. In the evaluation of function according to the JOA scale, the patient obtained a final score of 9 , this being the best score found in this study. (Table 2) The treatment goals outlined were: to promote functional reeducation, maintain and/or gain range of movement, promote balance, and improve gait.

Final assessment: After 2 and a half years, the patient was able to walk with a one-point cane, remaining with a Nurick score of 4. (Table 1) $\mathrm{He} / \mathrm{She}$ presented mild hypertonia in upper limb and moderate in the lower. Significant improvements were observed in the changes in sensitivity of both the upper limbs and the right lower limb, persisting only in the ankle and foot regions. (Figure 3) Regarding the reflexes, patellar and Achilles hyporeflexia were observed. The ranges of movement were incomplete in the hand pinch movement, in the right elbow and in supination. Left dorsiflexion was not performed. The patient was independent in performing ADLs, and was already able to turn over alone while lying, but needed the help of a cane to sit down and stand up. In the assessment of muscle strength, an improvement was seen on the right side in the adductor and abductor muscles of the shoulder when compared with the initial assessment. As for the lower limbs, an improvement was found in the hip flexors on the left side, and a worsening in the hip extensors and plantar flexors and extensors, also on left side. There was an improvement in the JOA score, where the patient in this evaluation obtained total score of 10 points due to an improvement in 


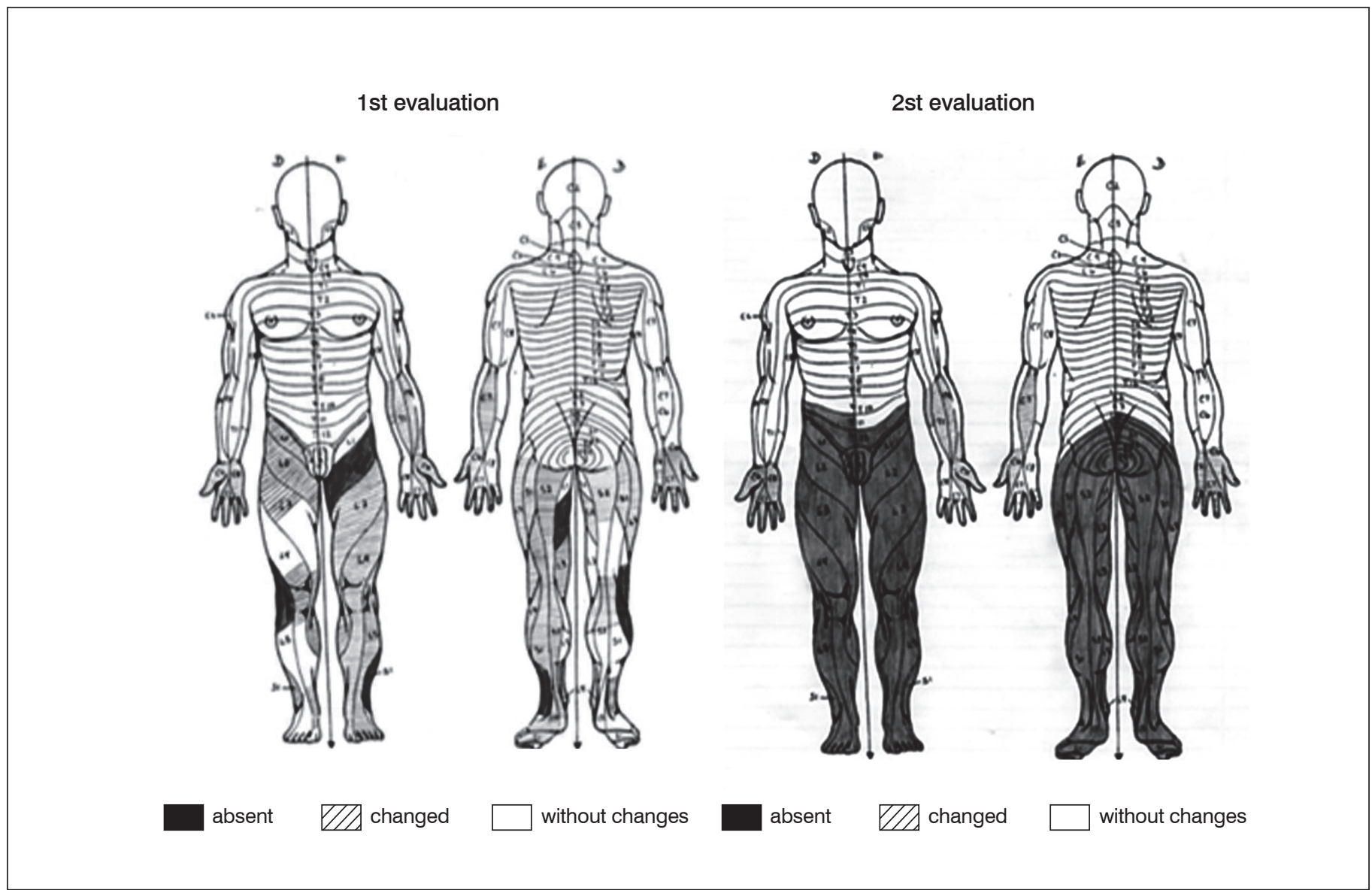

Figure 2. Sensory maps of patient 2 in the initial and final evaluations.

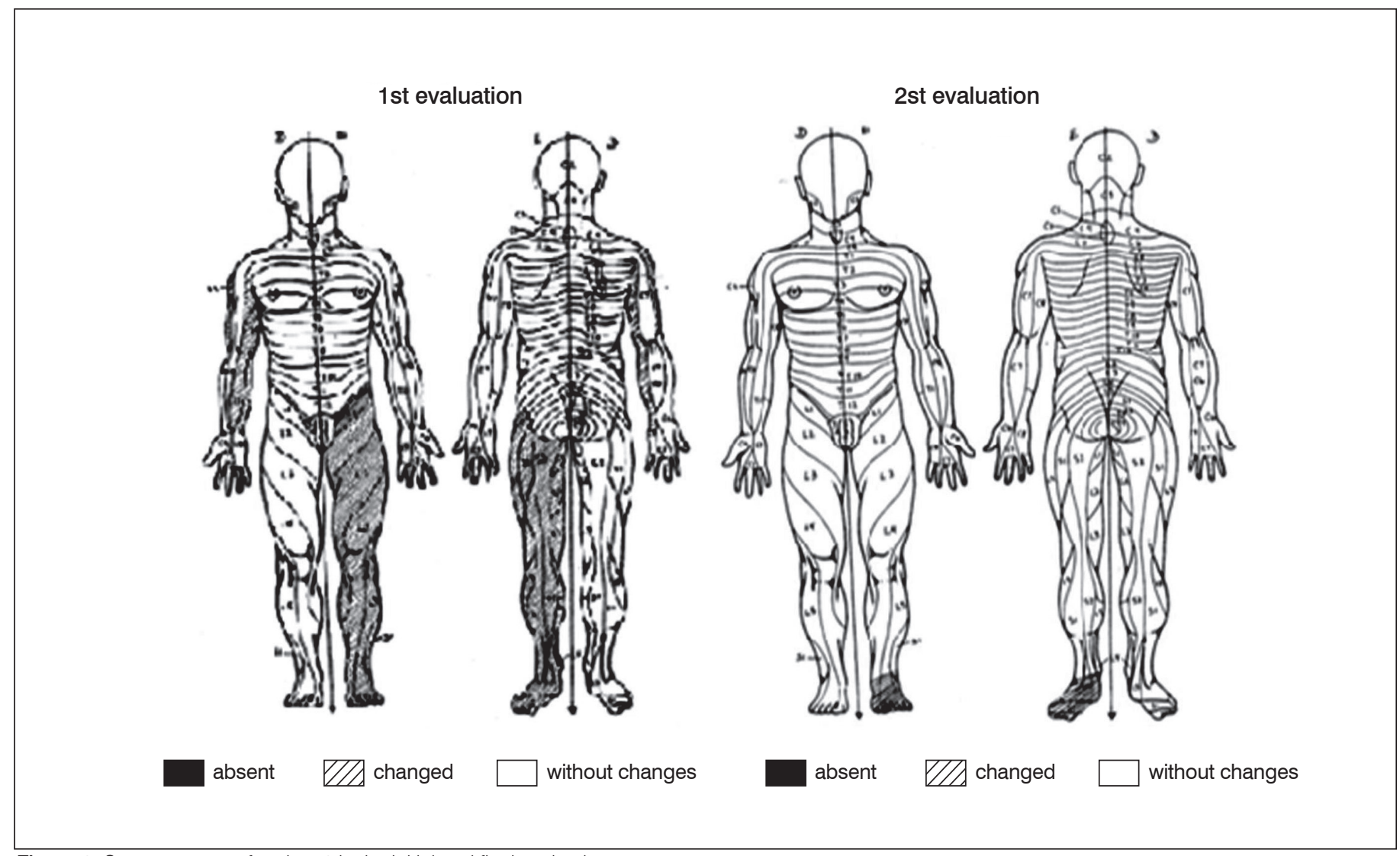

Figure 3. Sensory maps of patient 2 in the initial and final evaluations. 
item III A (Table 2). The treatment goals outlined in this phase were: to promote improvement of gait pattern, and to gain range of movement and muscle strength.

\section{DISCUSSION}

According to the cases presented here, the three patients received the diagnosis of CSM through complementary exams, which evidenced spondylotic changes associated with spinal cord degeneration. ${ }^{1}$ The most common changes found in CSM are: posterior bone neoformations that contribute to anterior spinal cord compression, hypertrophy and ligament calcification, which contributes to posterior-lateral compression and impairment of the intervertebral and zygapophyseal joints, causing stenosis of the vertebral canal, as well as the hypermobility of the segments above the damaged levels, which also causes spinal cord compression. ${ }^{2,7-9}$ These changes, besides explaining the clinical cases found, also highlight the fact that the disease has no typical pattern of progression, with wide variation occurring among patients, both in severity, and in locations where there is loss of spinal cord function.?

Comparing the figures with the dermatome maps, it is concluded that patients 1 and 3 showed an improvement in sensitivity after the surgery and physiotherapeutic treatment. Paradoxically, the symptoms of patient 2, who also had surgery and physiotherapy, worsened after the treatment. Considering the specific role of physiotherapy, there are few published studies on the conservative treatment of patients with myelopathy, partly due to the fact that the clinical symptoms of this patient tended to evolution of neurological symptoms, where to avoid such progression, the surgical procedure is performed early on as a measure to stabilize the patient. ${ }^{18}$

Matsumoto et al. ${ }^{18}$ conducted a study in which 27 patients with CSM received conservative treatment for at least 6 consecutive months. According to the study, $63 \%$ of their patients had positive results to the treatment and approximately $59 \%$ of patients experienced spontaneous reduction of cervical disc herniation. Persson et al. ${ }^{19}$ conducted a study comparing 110 patients with CSM between conservative surgical treatment and a cervical collar, and found no statistically significant difference between the groups even after 12 months of treatment, but an improvement in pain, functionality and humor of the patients was observed when comparing each group before and after the intervention.

In the conduct of treatment performed by the above studies, we found the use of the cervical collar for at least 8 hours continuously, for 3 months, reducing the time of use throughout the treatment, combined with rest when carrying out activities in general. ${ }^{18}$ Passive therapies were also performed for pain relief, such as massage and ice in the cervical region, application of transcutaneous electrical nerve stimulation (TENS), and ultrasound. Exercises were performed to strengthen and stretch the muscles of the neck, shoulder and upper extremities, as well as aerobic exercises to improve the patient's oxygen consumption. Instructions on ergonomic and postural corrections were given, in order to prevent complications, and during the treatment, gentle traction and mobilization of the cervical spine were performed. ${ }^{19}$

The resources and interventions used in this study include: 1) ability to turn over while lying and forms of independent locomotion as far as possible, 2) functional muscle strengthening, 3) lengthening of the muscles that have potential for retraction, and those that have already retracted, 4) passive mobilization of the articulations with little or no active movement, 5) sensory stimulation, 6) preventative and curative respiratory therapy, 7) relaxation of spastic or tense muscles, 8) pain relief, 9) postural reeducation aimed at control of the head and trunk, along with the balance training, and 10) use of activities adapted to the functions involved. It is important to highlight that there were some differences in the treatment conducts between all of the studies cited here, and ours. This was expected, as the disease evolution does not occur in the same way in every case 2. It was also seen that the patients in the studies presented received care only in upper limb. In our study, given that it is a review of the patients' records over the past 10 years of services provided in our clinic, we recorded all the procedures that were performed in the services, including those involving the lower limbs and trunk.

Such approaches should vary according to the level of commitment and the evolution of symptoms of each individual patient. Matsumoto also states that the physical treatment to be given should be carefully chosen, and even if the treatment is only conservative, it should considered in patients with a score of 2 or more in item II of the JOA scale, or a score of 2 on the Nutrick scale. Thus, constant reassessments are important, in order to adjust the proposed treatment, guidelines and adaptations for the patient with CSM.

It is clear that physiotherapy affects each patient differently, depending on the disease evolution and the individual's needs. The aim, though, is always to seek the greatest functionality possible because, as mentioned above, during the disease progression there may be times when the evolution of the spinal cord degeneration is stable, with improvement or maintenance of the signs and symptoms. For this reason, there are no treatment protocols in the literature, which is coherent, but there is a lack of texts detailing the disease, the possible clinical symptoms, and the physiotherapeutic interventions.

It is important to highlight the limitations of this study; because it is characterized as a report of clinical cases, the number of research subjects for whom records exist with a window of 10 years is low. Also, the assessments found are descriptive, reporting the current condition of the patient in both evaluations. Since there are numerous studies that compare surgical techniques and conservative treatment for the patient with spondylotic cervical myelopathy, ${ }^{20}$ it is necessary to conduct further studies that describe and compare which techniques and methods of physiotherapy treatment are most indicated for patients with this disease, even if it is only in a descriptive way, to guide future professionals and researchers.

\section{CONCLUSION}

According to the findings of this study, and supported by the literature, it is consistent to say that CSM does not follow a clear pattern of evolution, and there may be several clinical differentiations in each case. Thus, the treatment should be individualized and properly grounded, to obtain the best results. But there are a common means of assistance available for this disease, such as strengthening the muscles to gain strength, stimulating the range of active or passive movement, increasing or maintaining functional independence, and preventing future functional losses as the disease progresses. These therapeutic tools should be registered, to make them available to other researchers, and even to clinical practice, to ensure the best therapeutic conduct in CSM.

All authors declare no potential conflict of interest related to this article.

CONTRIBUTION OF THE AUTHORS: RAO (0000-0003-0723-470X)* performed the bibliographic review, KF(0000-0001-9150-1211)*, DS(0000$0002-4988-1238)^{*}$ and PCS $(0000-0001-7759-4247)^{*}$ followed up the patients and gathered clinical data. GJL $(0000-0002-6914-7225)^{*}$ and LAPSS (0000-0002-7160-9556)* performed the review of the manuscript and contributed to the intellectual concept of the study. *ORCID (Open Researcher and Contributor ID). 


\section{REFERENCES}

1. Hochman M, Tuli S. Cervical Spondylotic Myelopathy: A Review. The Internet Journal of Neurology. 2004;4(1).

2. Emery SE. Cervical Spondylotic Myelopathy: Diagnosis and Treatment. J Am Acad Orthop Surg. 2001;9(6):376-88

3. Lees F, Turner JWA. Natural history and prognosis of cervical spondylosis. Br Med J. 1963;2(5373):1607-10.

4. Clarke E, Robinson PK. Cervical myelopathy: A complication of cervical spondylosis. Brain. 1956:79(3):483-510

5. Teresi LM, Lufkin RB, Reicher MA, Moffit BJ, Vinuela FV, Wilson GM, et al. Asymptomatic degenerative disk disease and spondylosis of the cervical spine: MR imaging. Radiology. 1987:164(1): 83-8.

6. Frymoyer JW. The Adult Spine: Principles and Practice. 2nd ed. Philadelphia: Lippincott-Raven; 1997.

7. Montgomery DM, Brower RS. Cervical myelopathy: clinical syndrome and natural history. Orthop Clin North Am. 1992;23(3):487-93.

8. McCormack BM, Weinstein PR. Cervical spondylosis. An update. West J Med. 1996;165(1-2):43-51.

9. Matsunaga S, Sakou T, Taketomi E. Clinical course of patients with ossification of the posterior longitudinal ligament: A minimum 10-year cohort study. J Neurosurg. 2004;100(3 Suppl Spine):245-8

10. Wolf BS, Khilnani M, Malis L. The sagittal diameter of the bony cervical spinal canal and its significance in cervicalspondylosis. J Mt Sinai Hosp NY. 1956;23(3):283-92.

11. Arnold JG Jr. The clinical manifestations of spondylochondrosis (spondylosis) of the cervical spine. Ann Surg. 1955;141(6):872-89.

12. Crandall PH, Gregorius FK. Long-term follow-up of surgical treatment of cervical spon- dylotic myelopathy. Spine. 1977;2(2):139-46.

13. Penning L. Functional Pathology of the Cervical Spine. Baltimore: Williams and Wilkens: 1968

14. Fujiwara K, Yonenobu K, Ebara S, Yamashita K, Ono K. The prognosis of surgery for cervical compression myelopathy: An analysis of the factors involved. J Bone Joint Surg Bri. 1989;71(3):393-8.

15. Emery SE, Bohlman HH, Bolesta MJ, Jones PK. Anterior cervical decompression and arthrodesis for the treatment of cervical spondylotic myelopathy: Two to seventeen-year follow-up. J Bone Joint Surg Am. 1998;80(7):941-51.

16. Nurick $\mathrm{S}$. The pathogenesis of the spinal cord disorder associated with cervical spondylosis. Brain. 1972;95(1):87-100.

17. Hukuda S, Mochizuki T, Ogata M, Shichikawa K, Shimomura Y. Operations for cervical spondylotic myelopathy: a comparison of the results of anterior and posterior procedures. J Bone Joint Surg Br. 1985;67(4):609-15.

18. Matsumoto M, Chiba K, Ishikawa M, Maruiwa H, Fujimura Y, Toyama Y. Relationships Between Outcomes of Conservative Treatment and Magnetic Resonance Imaging Findings in Patients With Mild Cervical Myelopathy Caused by Soft Disc Herniations. Spine (Phila Pa 1976). 2001;26(14):1592-8.

19. Persson LCGR, Carlsson CA, Carlsson JY. Long-Lasting Cervical Radicular Pain Managed With Surgery, Physiotherapy, or a Cervical Collar: A Prospective, Randomized Study. Spine (Phila Pa 1976). 1997;22(7):751-8

20. Chagas H, Domingues F, Aversa A, Fonseca ALV, Souza JM. Cervical spondylotic myelopathy: 10 years of prospective outcome analysis of anterior decompression and fusion. Surg Neurol. 2005;64 Suppl 1:S1:30-5. 